\title{
Predicting Switching Behaviour of e-Service Users toward m-Services: An Empirical Investigation
}

\author{
Mutlaq B. Alotaibi \\ Al Imam Mohammad Ibn Saud Islamic University (IMSIU), Riyadh, Saudi Arabia. \\ * Corresponding author. Tel:: 966112586824; email: motaibi@imamu.edu.sa \\ Manuscript submitted July 10, 2016; accepted January 5, 2017. \\ doi: $10.17706 /$ jcp.13.1.100-115
}

\begin{abstract}
Although M-services have gained remarkable attention, recent advancements in mobile computing are competing against raised expectations. Little attention in the current literature has been given to the expectations of cost and benefits to determine switching behaviour towards M-services. Drawing upon prior theories of switching behaviour, the current research investigates the switching factors (inhibitors, enablers and social and personality aspects) by empirically examining a proposed research model using structural equation model (SEM) techniques. In order to examine the model, a survey data set of seven hundred and fifty $(n=750)$ responses was collected by means of an online questionnaire in Saudi Arabia. Results, herein, indicate that intention to switch to M-services can be predicted by expected switching cost (ESC), expected switching benefits (ESB), social influence (SI) and personal innovativeness (PI). Two groups consisting of three switching inhibitors and three switching enablers were demonstrated to be antecedents of the ESC and ESB respectively. All proposed relationships within the research model have been supported by empirical data.
\end{abstract}

Key words: Enablers, inhibitors, m-services, mobile, switching behaviour.

\section{Introduction}

With the rapid development of information and communication technology (ICT), M-services have evolved to supplement the traditional web channel, and ultimately to generate opportunities of value and revenue creation [1]. The M-services market has been growing rapidly in Saudi Arabia, where the mobile penetration rate reached $171 \%$ in 2014, with 53 million mobile subscribers [2]. Globally, it is estimated that M-services will extend to reach more than half of the world's population by 2020 [3]. The value of M-services is critically determined by the time of adoption, as the first adopters gain considerable benefits over late adopters [4]. M-services are regarded as an extension to traditional E-services, which, given this importance, allows individuals to choose between the two channels to maximize gains or minimize losses [5]. Although switching to the mobile channel involves a trade-off, recent studies found that E-service users exhibit increasingly positive switching attitudes towards M-services [6]. In summary, the mobile channel has been shown to be a vital communication channel to which E-service users have been attracted to migrate.

The decision to switch to M-services is influenced by several belief factors that encourage (motivators) or hinder (hygiene factors) the switching intention [7]. For example, using a mobile television (TV) instead of a traditional TV requires a certain transmission speed in order to match the user's expectations of service quality, and hence motivate the switching behaviour [4]. On the other hand, lacking the required service 
quality level (transmission speed) might hinder the switching intention towards the new model of TV watching, irrespective of the intrinsic motivation of mobility [4]. Despite the effect of enablers and inhibitors, it is seen as incomprehensive to model switching behaviour in the absence of cultural, social and personality factors. Few M-service studies have investigated the switching behaviour of E-service users towards M-services with a comprehensive model that comprises enablers, inhibitors and social aspects of switching behaviour. Therefore, it can be said that a gap in the literature has been identified and the current study attempts to fill it.

The purpose of this research is to assess the factors affecting users' switching behaviour from the traditional online service delivery model to the mobile channel. It provides in-depth understanding of the determinants of switching intention in the context of M-services. Furthermore, the present study examines whether the intention to switch to M-services (ISM) is related to variables such as expected switching costs (ESC), expected switching benefits (ESB), social influence (SI) and personal innovativeness (PI). In addition, the current study examines determinants of the ESC through a group of inhibitors, namely perceived fees (PF), cognitive effort (CE) and perceived risks (PR). It also identifies antecedents of the ESB using a set of enablers, including perceived mobility (PM), enjoyment (EN) and time convenience (TC). The contributions of this study include: (1) enrichment of the understanding related to the switching behaviour of E-service users towards mobile channels; (2) validation of switching behaviour theories in the context of M-services; and (3) the outcome of this research is of paramount importance to M-service researchers and practitioners.

The remainder of the paper is organized as follows. The next section presents theoretical foundations, including background knowledge of M-services and related theories of switching behaviour. This is followed by the research model and hypotheses in the third section, whereby a description of the conceptual model is provided and theoretical justifications of the relations between variables are discussed. Details of the research design are presented in the fourth section, including the research instrument, sample characteristics and a presentation of reliability measures. The model testing results is then described in section five. Research findings and implications are discussed in section six, followed by conclusions and final remarks in section seven.

\section{Theoretical Background}

\subsection{Mobile Services}

Online services are delivered to the end-user by means of fixed and mobile Internet channels, representing E-services and M-services respectively [8]. Historically, the fixed-Internet channel aimed to add a virtual dimension to bricks and mortar businesses, through which the user could accomplish tasks thorough the web and avoid visiting the physical location of the service provider [5]. In fact, the mobile-Internet channel aims to add the ubiquity dimension to the fixed-Internet channel by leveraging the time and location flexibility of the mobile channel [5]. Mobile channels bring salient benefits to the end-user, such as portability, localization and flexible connectivity [1]. Portability refers to the distinct feature of mobile devices that can be transported and conveyed in a way that makes the user able to use them on the move [1]. Localization denotes the mechanism of determining the location of the mobile devices in order to facilitate the adaptation of contents or functionalities of the mobile application accordingly [1]. Flexible connectivity refers to the ability of a mobile terminal to gain instant access to the global Internet, irrespective of the time and location of the connection request [1]. In summary, ubiquitous M-services offer considerable advantages to the end-user in comparison with traditional E-services.

Despite the great potential of M-services, its adoption faces several technical challenges. In particular, the switch from E-services to M-services involves a trade-off [1]. In usability engineering, mobile devices limit the interaction with mobile applications, due to the smaller screen size, particularly for tasks that required 
higher interaction and cognitive effort [9]. Furthermore, mobile devices have limited computing power and shorter battery life, compared with traditional desktop computing, which negatively affects the performance of mobile software [10]. These issues are coupled with uncertainty factors related to the limited protection of privacy and data storage, which inhibit the adoption of M-services [11]. In summary, it can be said that M-services are useful in situations where time and location are critical, interaction is simple, and the completion of tasks on the move is required.

\subsection{Theories of Switching Behaviour}

Research on switching behaviour asserts that intentions and attitudes towards switching from one technology to another are determined by several factors categorized under two main clusters: enablers (motivators) and inhibitors (hygiene factors) [7]. This stream of research follows the two-factor theory, which was derived from the theory of work motivation [7], [12]. Although the notation of enablers and inhibitors is seen as incomprehensive compared with the complex nature of switching decisions, recent studies have supplemented this model with social aspect and personality factors in order to better model the switching behaviour [13]. Another stream of research emphasizes that intention to switch is shaped by several factors aggregated into three key classes: push, pull and mooring factors. In fact, this stream adopted the push-pull-mooring (PPM) framework, which is derived from the human migration literature [14]. The PPM framework is similar to the two-factor theory, as the push factors represent the enablers that motivate the switching behaviour, while the pull factors represent the inhibitors that hinder the migration decision to the new substitutes. In addition, the PPM framework tackles the complexity of migration behaviour by incorporating cultural, social, and spatial aspects of switching behaviour under the mooring effects [14]. In summary, although switching behaviour research adapted theories from different paradigms, it involved considerable similarity, with respect to determining switch intentions using enablers (push effects), inhibitors (pull effects) and supplementing them with social aspects and personality factors (mooring effects).

A great deal of research has been conducted to investigate switching barriers as well as customer loyalty and retention, as opposed to the switching intention [15]. It is argued that loyalty and customer retention theories are distinct from the switching theories, yet they are in a way interrelated, because they all model and explain the user's post-adoption behaviour [13]. It is noteworthy that customer loyalty is complex and its dimensions vary from one context to another, such as brand loyalty [16] and service provider loyalty [17]. In general, it is commonly agreed that customer loyalty of IT products is influenced by satisfaction and relative advantage of incumbent IT, irrespective of the application domain [15]. Similarly, studies of continuance intention to use IT built their models based on satisfaction and dissatisfaction of the incumbent IT, in accordance with the expectation-confirmation theory (ECT) proposed by [18]. In summary, the switching literature is closely related to the customer loyalty and retention literature, as well as the post-adoption behaviour models of continuing usage of IT products.

\section{Research Model and Hypotheses}

\subsection{Conceptual Model}

The proposed model assumes that the intention to switch towards M-services (ISM) is influenced by four key factors: ESC, ESB, PI and SI. With respect to the ESC and ESB, prior research has suggested that both constructs are incorporated within perceived value (PV) of M-services [19]. In the current literature, the PV construct comprises two components: sacrifices and benefit components, which represent the ESC and ESB respectively [19]. In general, the switching literature assumes that the user will evaluate both the ESC and ESB in order to take the switching decision towards new substitutes. This argument is valid if the new 
technology substitutes the incumbent IT; therefore, some scholars introduced satisfaction with the incumbent IT as an influential factor [13]. However, the current model assumes that M-services are not modelled as a full substitute of the online channel, rather, it serves as a supplementary channel. Therefore, elements related to the satisfaction with incumbent IT were excluded.

Despite the effect of the ESC and ESB, several social, cultural and personality factors have an important role to play, such as the PI and SI. Prior research suggested that both the PI and SI could be introduced as control variables [13]. However, the current research modelled the two factors as predictors of the ISM, due to contextual elements related to IT adoption behaviour in developing countries. In fact, empirical evidence from recent studies showed that individuals in developing countries are strongly influenced by their social structure, with regard to their intention to adopt mobile technologies [11]. Similarly, personality factors, including PI, have been shown to have a considerable effect on adoption behaviour [20]. In summary, both the PI and SI reflect the mooring effects within the PPM framework, while the ESC and ESB represent the pull and push effects respectively.

\subsection{Hypothesis Development}

Fig. 1 shows the research model with ten hypotheses and the subsequent sections will provide empirical evidence supporting the proposed relationships between the variables.

The ESC refers to the sacrifices that the consumer is anticipating to make in order to shift from the electronic means of service delivery to the mobile channel [21]. The ESC involves monetary or non-monetary components [19]. The former represents the financial sacrifices expended when switching the model, whereas the latter covers several factors related to effort and resource expenditure as well as uncertainty concerns (risk perception) [19]. Furthermore, the ESC captures the concept of the sacrifices component within the PV construct discussed by several technology adoption models [19]. In general, the perception of switching costs is determined by several inhibitors that hinder the switching attitudes and intentions [13]. As mentioned earlier, the ESC represents switching inhibitors to the new technology. In particular, the switching inhibitors vary from one field to another. For example, perceived fee (PF), cognitive effort (CE) and perceived risks (PR) were found to be among the inhibitors of switching behaviour towards M-services [21, 22]. The PF represents the monetary component of the ESC, while CE and PR represent the non-monetary components. The next section will present arguments related to the relationship between the ESC and its determinants: PF, CE and PR.

In terms of monetary sacrifices, the cost factor PF is derived from the marketing literature, particularly the adaptation-level theory [21]. The M-service fee perception is affected by an internal reference price (IRP) that consumers usually possess based on prior experience with similar products, such as the cost of their Internet connection [23]. Experienced mobile consumers tend to shape their attitude towards M-service fees by comparing them with the IRP, while their inexperienced counterparts are unable to judge the pricing scheme [23]. It is noteworthy that perceived fee differs from perceived price. The former refers to the monetary spending on E-service usage, while the latter denotes the cost of purchasing the actual product or service [23]. In mobile environments, M-services can be offered for a fixed monthly subscription fee; or alternatively the service consumption can be metered by actual usage and priced per unit of time accordingly (usage-based pricing scheme) [24]. Given that the ESC represents the sacrifice component within the PV construct, earlier studies revealed that PF is negatively associated with PV in the context of mobile technologies. For example, a study [21] on the adoption of mobile Internet found that the PF has a negative influence on the PV. This finding was supported by another study [23] on the adoption of mobile commerce. Further, the results obtained from a recent study [19] on the adoption of M-coupons in China demonstrated the existence of the negative association between PF and PV. Drawing upon that, the PF can be considered as one of the inhibitors of switching behaviour to M-services. Therefore, it can be hypothesized 
that the FC is positively associated with the ESC.

With regard to the CE role, CE is another non-monetary determinant of the ESC. CE denotes the sacrifices that consumers expended in overcoming the complexity of innovative technology, such as time, and physical and mental load [22]. Complexity denotes the perceived difficulties associated with the actual usage or learning of the new technology [25]. The term technicality is usually used interchangeably with the CE, as noted by Kim et al. (2007), where technicality is considered among the non-monetary sacrifices. More importantly, [23] supported that notion and revealed that technicality is negatively associated with the PV of M-services. Further empirical evidence supporting this finding was provided by [22], revealing the negative association between CE and PV of the M-channel. More recently, [26] presented empirical evidence that when the learning of operational procedures is required prior to adoption and usage, consumers tend to shape their negative attitudes towards mobile technology. Therefore, it can be hypothesized that the CE is a key predictor of the ESC of M-services.

In terms of risk sacrifices, the PR has been modelled as a key antecedent of the ESC, due to the uncertainty associated with the adoption of M-services. The PR, as an innate aspect of mobile environments, contributes to increasing the consumer's resistance to adopting M-services [27]. Prior research provided solid empirical evidence supporting the notion that the PR is negatively associated with the PV of M-services. For example, a study by Yang, Lu, Gupta, Cao, and Zhang (2012), on mobile payment adoption, found that the PR inhibits the tendency of mobile users to adopt M-services [28]. Furthermore, [23] provided strong evidence indicating that security risks hinder consumer trust toward the adoption of M-services more than performance risks. Supporting this finding, a study by Yang, Liu, Li, and Yu (2015) provided insight into the effect of different risk components, revealing that privacy and financial risks were among the key factors to negatively affect the PV of M-services [29]. More recently, a study by Yang, Yu, Zo, and Choi (2016) on the adoption of wearable devices found PR to have a negative effect on the PV, with almost equal path co-efficient estimates for the two components (performance risk and financial risk) [30]. In summary, the PR contributes negatively towards the consumer's perception of M-service value; hence, it can be considered as a key determinant of the ESC.

Based on the theoretical justifications related to inhibitors of switching behaviour, it can be theorized that the ESC can be predicted by PF, CE and PR; to illustrate, the following hypotheses were presented:

H1: Greater perceived fees of M-services will be associated with greater expected switching costs.

H2: Greater cognitive effort of M-services will be associated with greater expected switching costs.

H3: Greater perceived risk of M-services will be associated with greater expected switching costs.

The model of switching behaviour assumes a trade-off between positive and negative aspects of shifting from one status toward a new substitute [12]. The positive aspects refer to the ESB of the switch decision, whereas the negative aspects denote the ESC expended by the switching behaviour [12]. In particular, the switching literature revealed negative and positive perceptions of the ESC and ESB respectively, and provided empirical evidence supporting their influences on intention to switch to the new technology. For example, a study by Kim and Kankanhalli (2009) on user resistance towards IT adoption found that the ESC increased the resistance to adopt IT, which reflected the negative perceptions towards migration to the new status [31]. Furthermore, it also found that the ESB increased the positive perceptions of IT, hence improving the tendency to adopt it [31]. Another study [13] on consumer switch behaviour towards cloud computing provided salient evidence that the ESC has a negative direct effect on intention to switch from one status to another. In addition, the study demonstrated that the ESB was positively associated with the intention to switch towards cloud computing [13]. More recently, a study by Zhou (2016) on the switch behaviour from online stores to M-stores provided empirical evidence supporting the notion that the ESC is negatively associated with the intention to switch in the context of M-services [6]. In summary, the ESC would increase 
the consumer's resistance to switching towards M-services by maximizing the expected loss, while the ESB would improve the consumer tendency towards M-service migration by highlighting the utilities resulting from the switch behaviour. Therefore, these two factors can be regarded as key predictors of ISM.

Despite the intrinsic effects of both the ESC and ESB, there remains scope for further influence from social and personality factors to predict the ISM, namely the PI and SI. The SI refers to social pressures that affect individual decisions to switch towards a new service delivery model, like the mobile model. The PI denotes the willingness of individuals to experiment with new technologies, in this context M-services, earlier than their colleagues do. Earlier studies demonstrated that the PI and SI are key determinants of M-service switch intention. For example, a study by Ye and Potter (2007) on switching behaviour between web browsers found that the SI has a positive influence on attitudes toward switching to new substitutes in the context of web browsing[32]. Park and Ryoo (2013) suggested that both the SI and PI have positive effects on intention to switch to cloud computing [13]. A study by Xu, Li, Heikkilä, and Liu (2013) on the switching behaviour of online players towards social network games (SNG) found that the SI is a strong predictor of the intention to switch toward SNG in China [33]. In the context of M-services, a recent study by Liu, Zhao, Chau, Tang, and Jansen (2015) provided empirical evidence supporting the notion that increasing PI promoted positive attitudes towards adopting mobile technologies [19]. In summary, the ISM can be predicted by four main factors: ESC, ESB, SI and PI. Therefore, it can be hypothesized that the ESB, SI and PI have a positive impact on the ISM, while the ESC has a negative impact on the ISM. To illustrate:

H4: Greater expected switching costs will be associated with lower intentions to switch toward M-services.

H5: Greater social influence will be associated with greater intentions to switch toward M-services.

H6: Greater personal innovativeness will be associated with greater intentions to switch toward M-services.

H7: Greater expected switching benefits will be associated with greater intentions to switch toward M-services.

The ESB refers to the utilities that the consumer expects to gain as result of the migration from the online channel to the M-service delivery model [21]. It is noteworthy that the ESB captures the concept of the benefits component within the PV construct discussed by several technology adoption models [19]. In general, the perception of switching benefits is determined by several enablers that promote the switching attitudes and intentions [13]. Having said that the ESB reflects the motivation aspects of switching behaviour, motivations can be categorized into two main classes: utilitarian and hedonic [34]. The former denotes the functional needs of the user, such as efficiency, effectiveness and performance, while the latter denotes the hedonic needs, such as pleasure, excitement and entertainment [34]. The current research assumes that M-service switching behaviour is driven by not only utilitarian motivations, such as perceived mobility (PM) and time convenience (TC), but also hedonic motivations, such as perceived enjoyment (PE). This argument is consistent with related studies [19], [21], [22], [26], [35]-[37]. Theoretical justifications of the relationship between the ESB and its determinants (PM, PE and TC) are discussed in the following sections.

In switching literature, the PM is considered among the main predictors of the ESB, representing the key enabler of M-service switching behaviour. Given its importance, scholarly research provided strong evidence indicating the positive association between the PM and ESB. For example, a study by Dewan (2013) on the user's tendency to switching towards M-banking revealed that not only did the PM promote positive attitudes towards migrating to M-services, but also it was the strongest predictor of switching behaviour $(\beta=0.36)$ [35]. Similarly, [36] provided empirical evidence supporting the notion that mobility is the strongest predictor of the PV of M-services ( $\beta=0.413)$. More recently, [26] investigated the adoption of mobile social networks and found that the PM is positively related with the PV of M-Services. The study demonstrated that the PM is more related to the perceived utilitarian value of M-services $(\beta=0.31)$, compared with its power in predicting the perceived hedonic value of M-services $(\beta=0.13)$ [26]. It is noteworthy that the study merged 
the two convenience factors (time and mobility) under one construct, labelled as mobile convenience and split the perception of the M-service value into two separate constructs: utilitarian value and hedonic value [26]. In summary, it can be said that the PM is a utilitarian factor that positively influences the ESB of M-services.

In terms of the PE role, it was argued that users who perceive using mobile technology as enjoyable tend to form positive attitudes toward that technology, irrespective of any productivity consequences that might be encountered [38]. Enjoyment is an intrinsic benefit related to the perceived hedonic value of M-services, built around fulfilling users' emotional needs, such as pleasure, excitement and entertainment [39]. Earlier studies revealed that PE is positively associated with the PV in the context of mobile technologies. For example, [21] revealed that the PE is among the strongest predictor of the PV of mobile Internet. Furthermore, [19] provided empirical evidence supporting the notion that PE is the strongest predictor of the PV of M-services. Another argument by [37] suggested that the impact of PE on switching intention is mediated by pull effects, and supported the existence of a strong relationship between PE, pull effects and switching intention. In summary, it can be said that increased enjoyment belief is associated with increased perceptions of M-service switching benefits.

As for the TC, the M-channel is economically seen as more efficient than other channels in terms of the time spent on task accomplishment [40]. This could increase positive attitudes towards M-services, mainly for time-critical tasks and time sensitive markets [40]. Prior research suggested that the TC is positively associated with the ESB, as a utilitarian benefit related to efficiency in service delivery. For example, [22] investigated the value creation of M-services, with a particular focus put on the time dimension, and found that perceived TC is the strongest predictor of PV of M-services in the context of M-commerce. This notion is fully supported by [19] in the context of M-coupons, however, the study investigated the role of perceived convenience, which comprises both the time and effort savings within the convenience construct. In summary, it can be said that increasing time convenience would contribute to increasing positive perceptions of M-service benefits.

Drawing upon the arguments related to the enablers of M-service switching behaviour, it can be hypothesized that the ESB can be determined by PM, PE and TC. To illustrate:

H8: Greater perceived mobility of M-services will be associated with greater expected switching benefits. H9: Greater perceived enjoyment of M-Services will be associated with greater expected switching benefits. H10: Greater time convenience of M-Services will be associated with greater expected switching benefits.

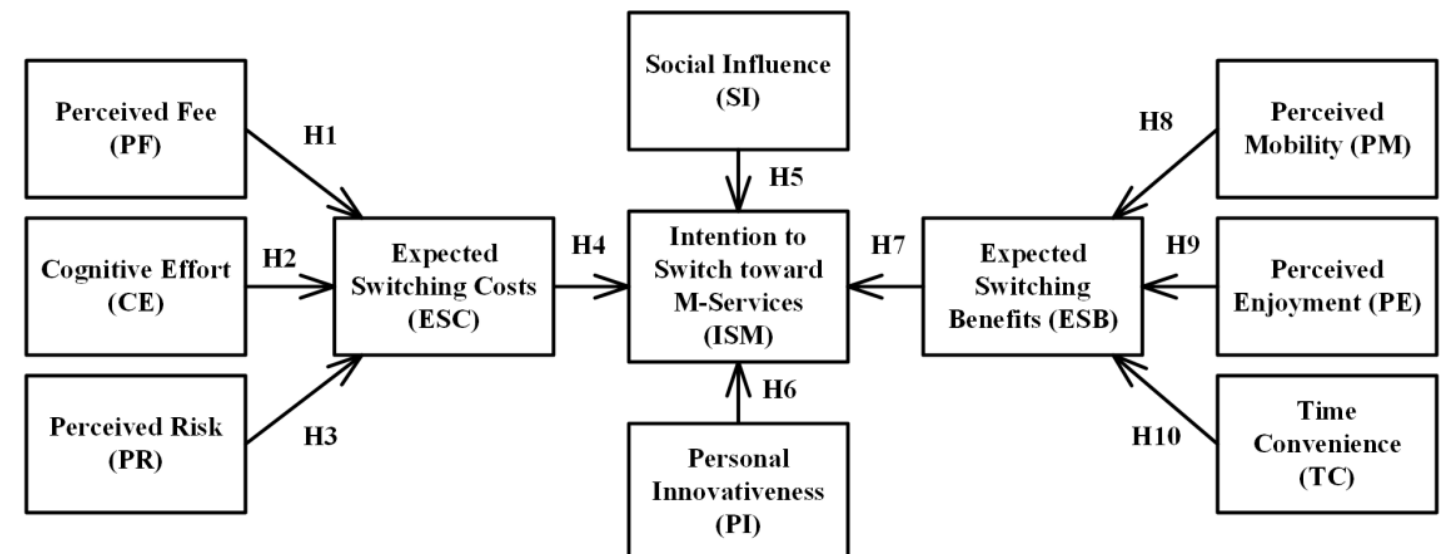

Fig. 1. Research model.

\section{Research Design}

As quantitative research, this empirical study utilized structural equation modelling (SEM) techniques to 
quantitatively examine the research model [41].

\subsection{Research Instrument}

Using latent variables and indictors, a research instrument was devised, especially for this study, in order to collect empirical data, as shown in Appendix 1. The scales of ESC, ESB, SI and PI were adapted from prior research in switching behaviour [13]. Similarly, the scales for PM [26], [42], PE [21], TC [22], PR [29], CE [26] and PF [21] were adapted from related studies. To arbitrate the instrument, a panel of experts reviewed the scales in order to validate content and ensure consistency. Several comments were received from the experts regarding sentence structure and the duplication of some items. Finally, an online questionnaire was developed, after the expert reviews were addressed, consisting of four parts: (1) introductory paragraph; (2) demographics (gender, IT background, age, education and monthly income); (3) switching constructs and items (ESC, ESB, SI, PI, PM, PE, PR, CE and PF); and (4) comments section. Items within the second section (switching factors) utilized a seven-point Likert-type scale ranging from 'strongly agree' to 'strongly disagree' [43]. The online questionnaire was distributed over the Internet by means of social media, electronic mails (E-mails) and ICT forums. Initially, eight hundred and thirty two $(n=832)$ responses were received during a three-week period. A considerable number of responses $(n=82)$, almost $10 \%$ of the initial patch, were disqualified, due to incompleteness and lack of validity. As a result, the sample size was seven hundred and fifty $(n=750)$ valid, consistent and complete responses.

\subsection{Sample Characteristics}

Table 1 shows the main characteristics of the sample. At a glance, the number of respondents varies among the five demographic variables. The distribution of respondents in two variables, namely IT background and monthly, was balanced, while the other variables (namely gender, age and education) lack the balance in respondents' distribution among categories. In fact, it can be seen from the table that two-thirds of the sample set were men, representing double the number of women. In addition, over half of the sample comprised participants with a solid IT background, reflecting a balanced distribution of the respondents. Furthermore, it can be seen from the table that most of the respondents came from younger generation ( $85 \%$ of the sample), as almost half of the sample were aged between 25 and 34; and over $35 \%$ of the sample were aged between 18 and 24. It was also found that most of the respondents were highly educated individuals, since over $70 \%$ of the respondents held a bachelor's degree and $12 \%$ a master's degree. Monthly income of the respondents showed a balance between income categories, as most the categories represented at least $10 \%$ of the sample. In summary, the main characteristics of the sample were revealed by five demographic variables.

Table 1. Sample characteristics

\begin{tabular}{llll}
\hline \hline Respondent demographics & & Frequency & Percent \\
\hline & Total & 750 & 100.0 \\
\hline Gender & Male & 505 & 67.3 \\
\hline Background & Female & 245 & 32.7 \\
\hline & Computing and technology & 391 & 52.1 \\
\hline Age & Other backgrounds & 359 & 47.9 \\
\hline & less than 17 & 21 & 2.8 \\
\hline & $18-24$ & 280 & 37.3 \\
\hline & $25-34$ & 362 & 48.3 \\
\hline Education & $35-44$ & 72 & 9.6 \\
\hline & $45-54$ & 12 & 1.6 \\
\hline & 55 and above & 3 & 0.4 \\
\hline & High school or under & 65 & 8.7 \\
\hline & Two years diploma & 40 & 5.3
\end{tabular}




\begin{tabular}{llll}
\hline & Bachelor & 533 & 71.1 \\
\hline & Masters & 91 & 12.1 \\
\hline PhD & 21 & 2.8 \\
\hline Monthly Income & 2,000 (Saudi Riyals) & 237 & 31.6 \\
\hline $2,000-4,999$ (Saudi Riyals) & 99 & 13.2 \\
\hline $5,000-8,999$ (Saudi Riyals) & 130 & 17.3 \\
\hline $9,000-11,999$ (Saudi Riyals) & 120 & 16.0 \\
\hline \hline & $12,000-14,999$ (Saudi Riyals) & 95 & 12.7 \\
\hline$>15,000$ (Saudi Riyals) & 69 & 9.2 \\
\hline
\end{tabular}

\subsection{Reliability and Validity of the Measurement Scale}

Table 2 shows the factor loading and indicators of the internal consistency and reliability. The estimates demonstrated considerable reliability and validity, as the factor loadings showed a satisfactory level higher than the recommended benchmark of 0.7 [44]. Internal consistency, convergent validity and discriminant validity were evaluated by Cronbach's alpha $(\alpha)$, composite reliability (CR) and correlation table respectively. In fact, evidence of fit was found, with regard to internal consistency, CR and the average variance extracted (AVE), where all exceeded the benchmarks with $\alpha>0.7, \mathrm{CR}>0.7$, and AVE $>0.5$ respectively [44]. With regard to the discriminant validity of the constructs, Table 3 shows the correlations between constructs. The table showed indicators of adequate validity measures, as the highest estimate was recorded for the variable being correlated with itself [44]. In summary, the scales exhibit adequate reliability and validity levels.

Table 2. Factor Loadings and Indicators of Internal Consistency and Reliability

\begin{tabular}{|c|c|c|c|c|c|c|}
\hline Construct & Item & Factor loading & t-value & $\alpha$ & CR & AVE \\
\hline \multirow[t]{4}{*}{$\mathrm{PM}$} & PM1 & 0.875 & 22.833 & 0.850 & 0.891 & 0.646 \\
\hline & PM2 & 0.924 & 26.267 & & & \\
\hline & PM3 & 0.857 & 25.242 & & & \\
\hline & PM4 & 0.898 & 24.769 & & & \\
\hline \multirow[t]{4}{*}{ PE } & PE1 & 0.926 & 25.445 & 0.810 & 0.880 & 0.631 \\
\hline & PE2 & 0.894 & 24.276 & & & \\
\hline & PE3 & 0.864 & 26.941 & & & \\
\hline & PE4 & 0.857 & 26.445 & & & \\
\hline \multirow[t]{4}{*}{ TC } & TC1 & 0.897 & 20.103 & 0.865 & 0.894 & 0.636 \\
\hline & TC2 & 0.841 & 24.122 & & & \\
\hline & TC3 & 0.819 & 23.39 & & & \\
\hline & TC4 & 0.867 & 23.538 & & & \\
\hline \multirow[t]{3}{*}{ ESB } & ESB1 & 0.778 & 21.045 & 0.805 & 0.813 & 0.596 \\
\hline & ESB2 & 0.859 & 23.505 & & & \\
\hline & ESB3 & 0.748 & 20.974 & & & \\
\hline \multirow[t]{3}{*}{ ISM } & ISM1 & 0.829 & 24.168 & 0.852 & 0.853 & 0.659 \\
\hline & ISM2 & 0.775 & 23.154 & & & \\
\hline & ISM3 & 0.825 & 24.982 & & & \\
\hline \multirow[t]{3}{*}{ SI } & SI1 & 0.757 & 21.447 & 0.861 & 0.817 & 0.546 \\
\hline & SI2 & 0.876 & 23.171 & & & \\
\hline & SI3 & 0.836 & 22.533 & & & \\
\hline \multirow[t]{4}{*}{ PI } & PI1 & 0.755 & 21.409 & 0.835 & 0.827 & 0.504 \\
\hline & PI2 & 0.718 & 20.971 & & & \\
\hline & PI3 & 0.798 & 21.991 & & & \\
\hline & PI4 & 0.818 & 22.101 & & & \\
\hline \multirow[t]{3}{*}{ ESC } & ESC1 & 0.724 & 22.667 & 0.794 & 0.831 & 0.621 \\
\hline & ESC2 & 0.782 & 23.426 & & & \\
\hline & ESC3 & 0.755 & 22.542 & & & \\
\hline \multirow[t]{3}{*}{ PR } & PR1 & 0.873 & 24.937 & 0.779 & 0.834 & 0.525 \\
\hline & PR2 & 0.739 & 23.209 & & & \\
\hline & PR3 & 0.793 & 22.227 & & & \\
\hline
\end{tabular}




\begin{tabular}{lllllll}
\hline & PR4 & 0.786 & 21.241 & & & \\
\hline CE & CE1 & 0.794 & 20.303 & 0.760 & 0.783 & 0.508 \\
\hline & CE2 & 0.785 & 21.891 & & & \\
\hline & CE3 & 0.855 & 23.209 & & & \\
\hline PF & PF1 & 0.872 & 23.027 & 0.801 & 0.723 & 0.521 \\
\hline & PF2 & 0.875 & 23.901 & & & \\
\hline \hline
\end{tabular}

Table 3. Correlations between constructs

\begin{tabular}{lllllllll}
\hline \hline Latent Variables & TC & CE & PF & SI & PI & PR & EN & PM \\
\hline TC & 0.797 & & & & & & & \\
\hline CE & -0.373 & 0.713 & & & & & & \\
\hline PF & -0.085 & 0.387 & 0.722 & & & & & \\
\hline SI & 0.405 & -0.060 & 0.101 & 0.739 & & & & \\
\hline PI & 0.526 & -0.334 & -0.027 & 0.392 & 0.710 & & & \\
\hline PR & -0.131 & 0.434 & 0.142 & 0.056 & -0.160 & 0.724 & & \\
\hline PE & 0.787 & -0.322 & -0.037 & 0.337 & 0.486 & -0.114 & 0.795 & \\
\hline PM & 0.793 & -0.321 & -0.079 & 0.322 & 0.467 & -0.051 & 0.700 & 0.803 \\
\hline \hline
\end{tabular}

\section{Model Testing Results}

Table 4 shows the model-fit indices. At a glance, the estimates for the quality-of-fit indicated a considerable fit of the model. First, the ratio of Chi-Square/Degree of Freedom $(\chi 2 / \mathrm{df})$ was greater than the critical value $(\chi 2 / \mathrm{df}<5.00)$ [45]. Secondly, the Root Mean Square Error Approximation (RMSEA) was estimated to be lower than the recommended benchmark (RMSEA $\leq 0.08$ ) [46]. Thirdly, the estimate for Standardized Root Mean Residual (SRMR) indicated a good fit [46]. Fourthly, the estimates for Incremental Fit Index (IFI), Comparative Fit Index (CFI) and Tucker Lewis Index (TLI) were greater than the benchmark of 0.90 [45], with values of $0.948,0.948$ and 0.940 , respectively. Finally, the estimates for Normed Fit Index (NFI) and Goodness of Fit Index (GFI) were higher than the acceptable level of 0.90 [46]. In summary, the model exhibits a good fit in accordance with eight quality-of-fit measures.

Table 4. Model-Fit Indices

\begin{tabular}{lll}
\hline \hline Quality-of-Fit Measure & Structural Model & Acceptable Value \\
\hline Chi-Square/Degree of Freedom $(\chi 2 / \mathrm{df})$ & 3.225 & $<5.00$ \\
\hline Root Mean Square Error Approximation (RMSEA) & 0.055 & $\leq 0.08$ \\
\hline Standardized RMR (SRMR) & 0.0413 & the smaller the better \\
\hline Incremental Fit Index (IFI) & 0.948 & $\geq 0.90$ \\
\hline Comparative Fit Index (CFI) & 0.948 & $\geq 0.90$ \\
\hline Tucker Lewis Index (TLI) & 0.940 & $\geq 0.90$ \\
\hline Normed Fit Index (NFI) & 0.926 & $\geq 0.90$ \\
\hline Goodness of Fit Index (GFI) & 0.918 & $\geq 0.90$ \\
\hline \hline
\end{tabular}

Fig. 2 shows the empirical results of the structural model. At a glance, it can be noticed that the results support the validity of the model as a theoretical base to predict switching intention to M-services. The predictive ability of the model was evaluated by $R^{2}$ estimates, which refer to the variability in a dependent variable explained by independent variables [41]. The model has three dependent variables: ESC, ISM and ESB. The estimate for the ESC was the lowest one, since the model can only explain $26 \%$ of the variance in the ESC. To clarify, the direct influence of the ESC antecedents (PF, CE and PR) accounts for $26 \%$ of the variability in the ESC. The model showed higher predictive ability with regard to the variance in the ISM and ESB. The model explains $70 \%$ of the variance in ISM. In other words, the direct effect of the ISM determinants (ESC, ESB, SI and PI) accounts for $70 \%$ of the variability in the ISM. Similarly, the model explains $69 \%$ of the variance in the ESB. That is, the influence of the ESB antecedents (PM, PE and TC) accounts for $69 \%$ of the 
variability in the ESB. In summary, the model exhibits an adequate predictive power with regard to variance in the ISM, ESB and ESC.

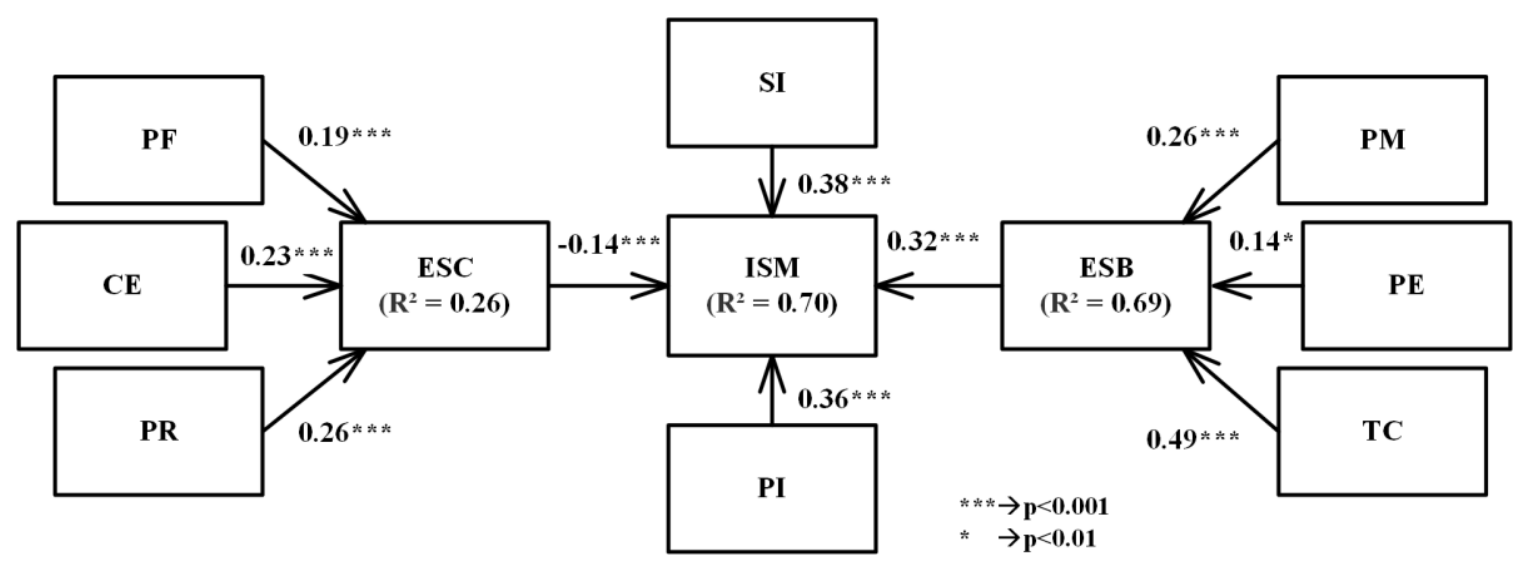

Fig. 2. Results of the structural model.

The path analysis was estimated to describe dependencies among M-service switching factors using coefficients Beta weight $(\beta)$. In general, most of the relationships of the proposed model were supported by empirical data. Apart from the relationship between the PE and the ESB, all relationships were found to be significant at the 0.001 level. In fact, the figure showed standardized $\beta$ estimates for the ESC, ISM and ESB dependencies. First, the three proposed antecedents of the ESC were shown to have a strong positive influence. In fact, results revealed that the path coefficient between the PF and the ESC was standardized $\beta=0.19$ with a significance level of $p<0.001$. In addition, the path coefficient between the CE and the ESC was standardized $\beta=0.23$ with a significance level of $p<0.001$. Similarly, the path coefficient between the PR and the ESC was standardized $\beta=0.26$ with a significance level of $p<0.001$. Secondly, the figure revealed that the ISM is negatively related to the ESC and positively associated with the SI, PI and ESB. In particular, the figure showed that the path coefficient between the ESC and the ISM has a negative value (standardized $\beta=-0.14$ ) with a significance level of $p<0.001$. In addition, the estimate for path coefficient between the SI and the ISM was shown to be positive (standardized $\beta=0.38$ ) with a significance level of $p<0.001$. Similarly, the path coefficient between the PI and the ISM was standardized $\beta=0.36$ with a significance level of $p<0.001$. Furthermore, the path coefficient between the ESB and the ISM was standardized $\beta=0.32$ with a significance level of $p<0.001$. Finally, the three proposed predictors of the ESB were shown to have a considerable influence. In fact, the results showed that the path coefficient between the PM and the ESB was standardized $\beta=0.26$ with a significance level of $p<0.001$. Furthermore, the path coefficient between the PE and the ESB was standardized $\beta=0.14$ with a significance level of $p<0.01$. With the highest value recorded, the path coefficient between the TC and the ESB was standardized $\beta=0.49$ with a significance level of $p<0.001$. In summary, the path analysis provided salient evidence supporting the proposed relationships within the structural model.

\section{Discussion}

Table 5 shows the hypothesis testing results. Overall, it can be noticed that evidence was found supporting acceptance of the ten hypotheses. In terms of hypotheses $\mathrm{H} 1, \mathrm{H} 2$ and $\mathrm{H} 3$, the three hypotheses were accepted, since the results indicated that the PF, CE and PR were positively associated with the ESC. In the context of this study, the three factors (PF, CE and PR) represent the inhibitors of the M-service switching behaviour, and therefore, are considered antecedents of the ESC. This finding is consistent with prior research [19], [21-23], [26], [28]-[30]. Another four hypotheses related to the ISM, namely H4, H5, H6 and H7, were also accepted. Results obtained from the hypotheses testing suggested that the ESC has a negative 
influence on the ISM, while the SI, PI and ESB were positively associated with the ISM. Evidence from the current study supported the notion that the four factors are key determinants of the ISM. This finding is compatible with empirical evidence obtained from related studies [6], [13], [19], [31]-[33]. With regard to hypotheses H8, $\mathrm{H} 9$ and $\mathrm{H} 10$, the three hypotheses were accepted, as the results indicated that the PM, PE and TC are positively associated with the ESB. It is noteworthy that the current study modelled those three factors as enablers of M-service switching behaviour, and therefore, represented the key antecedents of the ESB. This finding is in line with prior research [19], [21], [22], [26], [35]-[37]. In summary, the ten hypotheses examined during the course of this study were accepted; hence, the key predictors of the ISM, ESC and ESB were identified.

Table 5. Hypothesis Testing Results

\begin{tabular}{llllll}
\hline \hline Hypothesis & Path & Path coefficient $(\beta)$ & t-value & Accepted? & Notes \\
\hline$H 1$ & PF $\rightarrow$ ESC & $0.19^{* * *}$ & 3.188 & yes & Positive effects \\
\hline$H 2$ & CE $\rightarrow$ ESC & $0.231^{* * *}$ & 2.932 & yes & Positive effects \\
\hline$H 3$ & PR $\rightarrow$ ESC & $0.263^{* * *}$ & 4.245 & yes & Positive effects \\
\hline$H 4$ & ESC $\rightarrow$ ISM & $-0.141^{* * *}$ & -4.073 & yes & Negative effects \\
\hline$H 5$ & SI $\rightarrow$ ISM & $0.379^{* * *}$ & 10.61 & yes & Positive effects \\
\hline$H 6$ & PI $\rightarrow$ ISM & $0.358^{* * *}$ & 9.344 & yes & Positive effects \\
\hline$H 7$ & ESB $\rightarrow$ ISM & $0.32^{* * *}$ & 8.854 & yes & Positive effects \\
\hline$H 8$ & PM $\rightarrow$ ESB & $0.26^{* * *}$ & 4.512 & yes & Positive effects \\
\hline$H 10$ & PE $\rightarrow$ ESB & $0.138^{*}$ & 2.459 & yes & Positive effects \\
\hline \hline
\end{tabular}

Although this research is significant in explaining M-service switching factors, it encountered several limitations. For example, the sample does not reflect the population in a truly representative way (sample selection bias), as most of the sample comprised men and young individuals. This bias can be attributed to the context of Saudi Arabia, in which most of the population are young and women have lower involvement in the IT domain than men do [47]. Another limitation of this research is related to the common method bias [48], because the study was not longitudinal and measurements of the variables shared the same method (self-reported measures). Despite the limitations, this study proposed new directions for further research. One possible extension of this research could incorporate social and cultural aspects of M-service adoption. In addition, investigating M-service switching behaviour from the organizational perspective merits further investigation.

\section{Conclusion}

The purpose of this paper was to explore the factors influencing switching behaviour of E-service users towards M-services. Based on an extensive literature review, a theoretical model was proposed, incorporating major switching factors, such as switching inhibitors, switching enablers and social, cultural and personal factors. SEM analysis techniques were utilized to examine whether the model fit a survey data set of seven hundred and fifty $(n=750)$ participants. Results herein indicated that the model is valid to predict switching behaviour towards M-services, with ten hypotheses being supported by empirical data, and hence being accepted. The outcome of this research provides insight into negative, positive and social aspects of consumer switching behaviour to enrich the theory and practice of M-service adoption. Major managerial implications were highlighted and further directions for research recommended.

\section{Appendix 1 (Variables and indicators)}

PM [26], [42]

PM1. Mobility of M-services makes it possible to acquire real-time data.

PM2. It is convenient to use M-services anytime and anywhere. 
PM3. Mobility is an outstanding advantage of M-services.

PM4. In general, using M-services would be convenient for me.

PE [21]

PE1. I have fun interacting with M-services.

PE2. Using M-services provides me with a lot of enjoyment.

PE3. I enjoy using M-services.

PE4. Using M-services bores me (Reversed).

TC [22]

TC1. Using M-services is an efficient way to manage my time.

TC2. Using M-services would be convenient for me.

TC3. Using M-services would allow me to save time.

TC4. Using M-services would make transactions less time consuming.

ESB [13]

ESB1. Changing to M-services will enhance my effectiveness on the job compared to working in the transitional E-services way.

ESB2. Changing to new way of working with M-services will enable me to accomplish relevant tasks more quickly than working in the transitional E-services way.

ESB3. Changing to new way of working with M-services will improve the quality of the work I do compared to working in the transitional E-services way.

ISM [13]

ISM1. I intend to increase my use of M-services in the near future.

ISM2. I intend to invest my time and effort to M-services.

ISM3. I intend to switch from E-services to M-services.

SI [13]

SI1. People who influence my behaviour (friends, colleagues, etc.) think that I use M-services.

SI2. People who influence my behaviour think that I should switch from E-services to M-services.

SI3. People who influence my behaviour expect me to switch from E-services to M-services.

PI [13]

PI1. If I heard about a new information technology, I would look for ways to experiment with it.

PI2. Among my peers, I am usually the first to try out new information technologies.

PI3. In general, I am not hesitant to try out new information technologies.

PI4. I like to experiment with new information technologies.

ESC [13]

ESC1. It will take a lot of time and effort to switch to M-services.

ESC2. Switching to M-services can result in unexpected hassles.

ESC3. I will lose a lot of my work if I am to switch to M-services.

PR [29]

PR1. The transmission of data over my mobile phone will be unsafe.

PR2. I have confidence in the security of my M-Services. (Reserved)

PR3. I am worried that information I provide for M-Services will be delivered to the wrong people.

PR4. I will be uncomfortable making use of mobile payments.

\section{CE [26]}

CE1. I do not think that using M-Services is complicated. (Reserved)

CE2. Understanding how to use M-Services requires much effort.

CE3. I believe that learning about how M-Services work will be difficult.

PF [21]

PF1. The fee that I have to pay for the use of M-services is too high.

PF2. I am pleased with the fee that I have to pay for the use of M- services (Reversed)

\section{References}

[1] Picoto, W. N., Bélanger, F., \& Palma-dos-Reis, A. (2013). M-business organizational benefits and value: A qualitative study. Journal of Organizational Computing and Electronic Commerce, 23, 287-324.

[2] CITC. Communications and Information Technology Commission (CITC) IT Annual Report 2014. From 
http://www.citc.gov.sa/English/MediaCenter/Annualreport/Documents/PR_REP_010Eng.pdf

[3] Moreno-Munoz, A., Bellido-Outeirino, F., Siano, P. \& Gomez-Nieto, M. (2016). Mobile social media for smart grids customer engagement: Emerging trends and challenges. Renewable and Sustainable Energy Reviews, 53, 1611-1616.

[4] Lin, T.-C., Wu, S., Wang, K.-I., \& Tsai, M.-C. (2015). Factors affecting third-generation mobile services: Applying the purchase intention model. Journal of Organizational Computing and Electronic Commerce, 25, 47-75.

[5] Huang, L., Lu, X., \& Ba, S. (2015). An empirical study of the cross-channel effects between web and mobile shopping channels. Information \& Management.

[6] Zhou, T. (2016). Understanding users' switching from online stores to mobile stores. Information Development, 32, 60-69.

[7] Hou, A. C. (2015). Switching motivations on instant messaging: A study based on two factor theory. Multidisciplinary Social Networks Research, eSpringer, 3-15.

[8] Reuver, De M., Ongena, G., \& Bouwman, H. (2013). Should mobile Internet be an extension to the fixed web? Fixed-mobile reinforcement as mediator between context of use and future use. Telematics and Informatics, 30, 111-120,

[9] Lee, D., Moon, J., Kim, Y. J., \& Mun, Y. Y. (2015). Antecedents and consequences of mobile phone usability: Linking simplicity and interactivity to satisfaction, trust, and brand loyalty. Information \& Management, 52, 295-304.

[10] Andreadis, I. (2015). Comparison of response times between desktop and smartphone users. Mobile Research Methods, 63.

[11] Malaquias, R. F., \& Hwang, Y. (2016). An empirical study on trust in mobile banking: A developing country perspective. Computers in Human Behavior, 54, 453-461.

[12] Chang, Y.-W., \& Hsu, P.-Y. (2016). Investigating switching intention to cloud enterprise information systems: An analysis at the organizational level. International Journal of Information Management.

[13] Park, S. C. \& Ryoo, S. Y. (2013). An empirical investigation of end-users' switching toward cloud computing: A two factor theory perspective. Computers in Human Behavior, 29, 160-170.

[14] Lai, J.-Y., \& Wang, J. (2015). Switching attitudes of Taiwanese middle-aged and elderly patients toward cloud healthcare services: An exploratory study. Technological Forecasting and Social Change, 92, 155-167.

[15] Lin, T.-C., Huang, S.-L., \& Hsu, C.-J. (2015). A dual-factor model of loyalty to IT product-The case of smartphones. International Journal of Information Management, 35, 215-228,.

[16] Saleh, M. A. H., Althonayan, A., Alhabib, A., Alrasheedi, E., \& Alqahtani, G. (2015). Customer satisfaction and brand switching intention: A study of mobile services in Saudi Arabia. Expert Journal of Marketing, 3, 62-72.

[17] Chen, Y.-M., Nhai, T., \& Jasmine, D. (2015). Determinant factors of customer satisfaction for mobile service providers. International Journal of Science Commerce and Humanities, 66-77.

[18] Bhattacherjee, A. (2001). Understanding information systems continuance: An expectation-confirmation model. MIS Quarterly, 351-370.

[19] Liu, F., Zhao, X., Chau, P. Y., Tang, Q., \& Jansen, J. (2015). Roles of perceived value and individual differences in the acceptance of mobile coupon applications. Internet Research, 25.

[20] Abu-Shanab, E., \&Pearson, J. (2009). Internet banking in Jordan: An Arabic instrument validation process. Int. Arab J. Inf. Technol., 6, 235-244.

[21] Kim, H.-W., Chan, H. C., \& Gupta, S. (2007). Value-based adoption of mobile internet: An empirical investigation. Decision Support Systems, 43, 111-126,. 
[22] Kleijnen, M., Ruyter, De K., \& Wetzels, M. (2007). An assessment of value creation in mobile service delivery and the moderating role of time consciousness. Journal of Retailing, 83, 33-46.

[23] Chunxiang, L. (2014). Study on mobile commerce customer based on value adoption. Journal of Applied Sciences, 14, 901-909.

[24] Ha, S., Sen, S., Joe-Wong, C., Im, Y., \& Chiang, M. (2012). Tube: Time-dependent pricing for mobile data. ACM SIGCOMM Computer Communication Review, 42, 247-258.

[25] Everett, M. R. (1995). Diffusion of innovations. New York.

[26] Lin, K.-Y., \& Lu, H.-P. (2015). Predicting mobile social network acceptance based on mobile value and social influence. Internet Research, 25, 107-130.

[27] Shin, D.-H. (2009). Towards an understanding of the consumer acceptance of mobile wallet. Computers in Human Behavior, 25, 1343-1354.

[28] Yang, S., Lu, Y., Gupta, S., Cao, Y., \& Zhang, R. (2012). Mobile payment services adoption across time: An empirical study of the effects of behavioral beliefs, social influences, and personal traits. Computers in Human Behavior, 28, 129-142.

[29] Yang, Y., Liu, Y., Li, H., \& Yu, B. (2015). Understanding perceived risks in mobile payment acceptance. Industrial Management \& Data Systems, 115, 253-269.

[30] Yang, H., Yu, J., Zo, H., \& Choi, M. (2016). User acceptance of wearable devices: An extended perspective of perceived value. Telematics and Informatics, 33, 256-269.

[31] Kim, H.-W., \& Kankanhalli, A. (2009). Investigating user resistance to information systems implementation: A status quo bias perspective. Mis Quarterly, 567-582.

[32] Ye, C., \& Potter, R. (2007). The role of habit in post-adoption switching of personal information technologies: A push, pull and mooring model. DIGIT 2007 Proceedings, 7.

[33] Xu, X., Li, H., Heikkilä, J., \& Liu, Y. (2013). Exploring individuals' switching behaviour: An empirical investigation in social network games in china. Proceedings of the 26th Bled eConference, Slovenia.

[34] Kim, Y. H., Kim, D. J., \& Wachter, K. (2013). A study of mobile user engagement (MoEN): Engagement motivations, perceived value, satisfaction, and continued engagement intention. Decision Support Systems, 56, 361-370.

[35] Dewan, S. (2013). Towards anchoring users' switching to mobile banking with expectancy theory. Proceedings of 24th Australasian Conference on Information Systems (1-11).

[36] Wang, C. (2014). Antecedents and consequences of perceived value in Mobile Government continuance use: An empirical research in China. Computers in Human Behavior, 34, 140-147.

[37] Hsieh, J.-K., Hsieh, Y.-C., Chiu, H.-C., \& Feng, Y.-C. (2012). Post-adoption switching behavior for online service substitutes: A perspective of the push-pull-mooring framework. Computers in Human Behavior, 28, 1912-1920.

[38] Wang, L., Yang, J., \& Yang, L. (2014). The important of enjoyment and mobility for continuance with mobile data services. WHICEB, 6.

[39] Sun, Y.-Q., Zhao, Y., Jia, S.-Q., \& Zheng, D.-Y. (2015). Understanding the Antecedents of Mobile Game Addiction: The Roles of Perceived Visibility, Perceived Enjoyment and Flow.

[40] Kang, J.-Y. M., Mun, J. M., \& Johnson, K. K. (2015). In-store mobile usage: Downloading and usage intention toward mobile location-based retail apps. Computers in Human Behavior, 46, 210-217.

[41] Kline, R. B. (2015). Principles and practice of structural equation modeling: Guilford publications.

[42] Park, E., \& Kim, K. J. (2014). An integrated adoption model of mobile cloud services: exploration of key determinants and extension of technology acceptance model. Telematics and Informatics, 31, 376-385.

[43] Lee, J. W., Jones, P. S., Mineyama, Y., \& Zhang, X. E. (2002). Cultural differences in responses to a Likert scale. Research in Nursing \& Health, 25, 295-306. 
[44] Hair, J. F., Black, W. C., Babin, B. J., Anderson, R. E., \& Tatham, R. L. (2006). Multivariate Data Analysis, Upper Saddle River, NJ, USA: Pearson Prentice Hall, 6.

[45] Bagozzi, R. P., \& Yi, Y. (1988). On the evaluation of structural equation models. Journal of the Academy of Marketing Science, 16, 74-94.

[46] Byrne, B. M. (2014). Structural Equation Modeling with Lisrel, Prelis, and Simplis: Basic Concepts, Applications, and Programming: Taylor \& Francis Group.

[47] Al-Gahtani, S. S., Hubona, G. S., \& Wang, J. (2007). Information technology (IT) in Saudi Arabia: Culture and the acceptance and use of IT. Information \& Management, 44, 681-691,.

[48] Podsakoff, P. M., MacKenzie, S. B., Lee, J.-Y., \& Podsakoff, N. P. (2003). Common method biases in behavioral research: A critical review of the literature and recommended remedies. Journal of Applied Psychology, 88, 879.

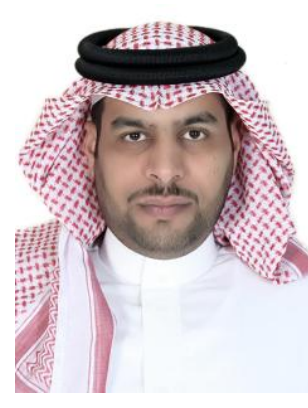

Mutlaq B. Alotaibi is an Associate Professor of Information Systems at Al Imam Mohammad Ibn Saud Islamic University (IMSIU). In 2010, he was appointed Head of the IS Department. In 2012, he was appointed as the Vice Dean for Academic Affairs at the College of Computer and Information Sciences. His main research interests are in the area of interactive systems, particularly in multimodal interaction and adaptive user interfaces. He is also interested in IS research, particularly consumer behaviour, and in the application of user acceptance of technologies. He has publications in the fields of, e-business and e-commerce, customer knowledge management, customer relationship management, cloud computing, mobile computing, and usability heuristics. 